\title{
EL PENSAMIENTO POLÍTICO VERDE
}

\author{
GREEN POLITICAL THOUGHT
}

Fernando León Jiménez

Recibido: enero de 2011.

Universidad Pablo de Olavide de Sevilla

Aceptado: abril de 2011.

fleojim@upo.es

Palabras claves: Equilibrio, ética, Pacto Natural, científicos, economía sostenible, solidaridad ambiental, sanciones adecuadas.

Keywords: Balance, Ethics, Natural Covenant, scientists, sustainable economy, environmental solidarity, appropriate sanctions.

Resumen: El riesgo que representa la acción humana del hombre moderno sobre el planeta es real y grave. En reacción a esta nueva realidad, los movimientos políticos verdes defienden un cambio de mentalidad. Parten de planteamientos esencialmente éticos y no tecnológicos, porque la raíz del problema es moral. En un plano político, defienden que hay que dignificar a la Naturaleza como sujeto de derechos, y proponen avanzar desde el tradicional «Pacto Social» a un nuevo «Pacto Natural» con el Planeta, descargando una especial responsabilidad en la defensa de estos valores sobre los científicos. Por fin, sostienen una economía sostenible que acepte los límites naturales del crecimiento, una solidaridad humanizada y ambiental con los países pobres y un cuadro de sanciones ambientales adecuado que no se olvide de las acciones de promoción.

Abstract: The risk posed by human activities of modern man on the planet is real and serious. In reaction to this new reality, green political movements advocating a change in mentality. Approaches are based essentially ethical and non-technical, because the root of the problem is moral. On a political level, they argue that we must restore the dignity of nature as a subject of rights, and propose to move from the traditional "Social Pact» to a new "Natural Covenant» to the planet by downloading a special responsibility to defend these values on scientists. Finally, maintain a sustainable economy that accepts the natural limits of growth, humane and environmental solidarity with poor countries and a table of appropriate environmental sanctions do not forget the promotion. 


\section{l. Notas introductorias}

El estado actual del medio ambiente planetario supone una amenaza real para la vida humana sobre la tierra. Esta evidencia científica convierte la protección del medio en el que desenvuelve en un objetivo prioritario para el conjunto de las naciones que componen la sociedad mundial. No es extraño, por tanto, que esta demanda se haya trasladado al ámbito del pensamiento y política, originando movimientos con perfiles desconocidos hasta ahora que tienen la protección de la naturaleza como objetivo de fondo y criterio de enfoque de cualquier problema.

Los avances tecnológicos de los últimos dos siglos han propiciado que el hombre tenga una capacidad para influir en el medio que sólo podía soñarse hasta hace poco. No quiere decir esto que todo juicio que merecen estos avances sean negativos: la medicina, ingeniería civil o los transportes son revoluciones muy beneficiosas que solamente pueden merecer un juicio positivo. Pero el abuso de estos avances, orientados en gran medida a la explotación intensiva de recursos finitos y no siempre renovables, también han comprometido el secular equilibrio natural y la supervivencia del hombre, que depende del mantenimiento de un básico estado de cosas ambiental.

En este capítulo, vamos a exponer cuáles son las notas comunes a los movimientos ecologistas, entendido como corrientes de pensamiento y acción política. Ciertamente, puede haber grupos y pensadores que tengan planteamientos originales no coincidentes con todos o algunos de los postulados que expresamos. Pero en términos generales, todos los que se identifican con el ecologismo y la defensa de la naturaleza comparten en alguna medida lo que aquí decimos, que debe tomarse, por tanto, como una síntesis de sus principios rectores básicos.

\section{El principio de prioridad ética}

Un postulado clave del pensamiento verde es la prioridad de la ética sobre la técnica.

Es imprescindible afrontar el problema ambiental desde una perspectiva esencialmente ética. Este enfoque ético asumen un carácter prioritario y preferente (esto es: anterior y superior) a cualquier perspectiva, incluida la jurídica. Y es que realmente toda medida política o jurídica medioambiental precisa reestructurarse de sus bases éticas para que sean realmente eficaces y reorientadas en un sentido ecológico. La necesidad de este enfoque ético primario la ha fundamentado de forma concisa y atinada en pensador Erich Fritz Schumacher: «El problema del deterioro ambiental no es principalmente un problema técnico; si lo fuera, no habría surgido de un modo tan agudo en las sociedades tecnológicamente avanzadas... Se origina en el estilo de vida del mundo moderno, que a su vez surge de las creencias básicas: su metafísica o su religión» (el subrayado es nuestro). ${ }^{1}$

Por tanto, el pensamiento verde es moraliza de la supervivencia: será relevante moralmente, y merece atención éti- 
ca, todo ente que pueda alterar las condiciones de vida sobre la Tierra hasta el punto de amenazar la vida de la humanidad. En efecto, el instinto de supervivencia es primario y superior a cualquier estructura valorativa o de conocimiento, y obligadamente debe tener una proyección moral, máxime cuando la supervivencia que puede verse comprometida es la de la especie humana en su conjunto. Que la supervivencia humana no se vea comprometida de forma inmediata de ninguna manera no debe interpretarse como una ausencia de amenaza; el dato del tiempo es relativamente irrelevante dentro del debate ambiental. Hay que considerar que de seguir así la situación, la fase más aguda de la crisis se terminaría manifestando, amenazando gravemente la supervivencia humana tarde o temprano. Es esencial comprender que los efectos del problema en todo caso se manifestarán oportuna o inoportunamente, y que el tiempo del que disponemos es un factor a sumar a todos los que conforman nuestra última oportunidad para corregir el problema.

De esta apertura de comprensión y miras dependerá la eficacia de la acción política futura para afrontar e problema ambiental, y que pueda colaborarse eficazmente desde el Derecho en la solución de la presente (y con toda seguridad futura) crisis ambiental. Afrontar la nueva realidad del problema ambiental desde la perspectiva ética adecuada es la única forma de encauzar la acción política y la legislación positiva en el sentido más atinado para superar esta crisis que amenaza a la humanidad.

Enlazando con lo anterior, el pensamiento verde apuesta por una visión totaliza- dora integral e interdependiente, que hay que trasladar desde la ecología a la Ciencia Política destinada al tratamiento de los problemas ambientales y no ambientales. Ética, Política, Derecho, Ecología y Economía no son realidades separadas, sino manifestaciones de un solo ser. Es la división de las disciplinas las que han distorsionado este enfoque unitario, sustituyéndolo por otro fragmentado. En efecto, la Política y el Derecho deben tener siempre presente la variable ambiental aunque aparentemente no quede implicada de forma directa en algunos contextos de acción. El carácter ubicuo y general de la temática ambiental la proyectan sobre todos los sectores de la vida humana, y todo abordaje jurídico o político de la misma exige, de suyo, la toma en consideración de las exigencias planteadas por aquella variable. $Y$ del mismo modo, el tratamiento de los problemas ambientales no puede ser unidimensional; éste debe implicar a todos los sectores y perspectivas, incluyendo en su programa de acción desde grupos ecologistas y ministerios de medio ambiente a cuerpos de seguridad e incluso ejércitos.

\section{3. ¿Cómo se protege a la naturaleza?}

Desde la perspectiva ética explicada, el medio ambiente debe estatuirse como un bien esencial en sentido jurídico y político.

Al disfrute de este bien tienen derecho todos los seres humanos. No obstante, su consideración como esencial no debe 
llevarnos a entender que cualquier manifestación de la naturaleza es sagrada y debe permanecer intocable. Más al contrario, el medio ambiente debe considerarse un bien jurídico primario solamente en su dimensión de soporte de los demás derechos, esto es, en la medida que crea las condiciones generales que sostienen la vida en general, y la humana en particular. Son las actuaciones sobre manifestaciones ambientales que pueden comprometer esta cualidad del medio ambiente de ser «hecho sustentador de derechos» las que deben ser prohibidas y castigadas con severidad por conculcar el derecho humano a un medio ambiente soporte de la vida o, si se prefiere, del derecho a la vida en su dimensión ambiental.

De ahí, que deba ser protegido desde la categoría conceptual de los derechos humanos, con todo o que implica de refuerzo de su protección (procedimientos especiales, rapidez en la tutela, regulación específica por Ley...). Ello no obsta, en ningún caso, a que las manifestaciones paisajísticas y culturales del medio ambiente deban ser adecuadamente protegidas aunque no sean esenciales para la vida. Pero no hay que protegerlas desde la categoría de los derechos humanos. Hay que reservar la protección desde este ámbito para las agresiones más importantes al medio natural y que comprometen más intensamente, sea directa o indirectamente, la vida humana. Este trabajo de delimitación jurídica de la protección del medio a través del sistema de derechos humanos está por hacer: «Los nuevos derechos fundamentales del futuro exigirán nuevos planteamientos doctrinales y proba- blemente expresiones y categorías que definan su propia naturaleza». ${ }^{2}$

Como punto de partida para avanzar en el futuro, es justo equiparar en una dimensión estrictamente ambiental los derechos de la persona a los derechos del Planeta, en cuanto que fórmula de protección recíproca sustentada sobre los mismos fundamentos biológicos de la vida. El daño que sufre una de ambas realidades es indicativo de la amenaza o paralelo deterioro sufrido por la otra. Esta circunstancia los aúna en sus necesidades y, en consecuencia, también en sus derechos: el fundamento de la protección del uno es, por tanto, el fundamento de la protección del otro. Contemplar a la persona y el Planeta como dos áreas de una misma realidad permiten fundir y confundir sus derechos, redefiniendo la dignidad nativa de ambos en un sentido unitario en el que cobran una nueva dimensión al amparo de la proyección del contenido del uno sobre el otro.

\section{Democracia y medio ambiente}

Es imprescindible e inaplazable una reformulación de las bases esenciales de la teoría democrática moderna desde una perspectiva ecológica.

El sufragio universal, directo y secreto, las reglas de las mayorías, el respeto al Estado de Derecho y a los derechos humanos, la separación de poderes, la realización real y efectiva de la libertad e igualdad de los individuos... son signos distintivos de una idea nuclear y elemen- 
tal de democracia que actualmente se consideran irrenunciables, fruto de una labor progresiva de ensanche del contenido original y limitado del concepto de democracia (fundamentalmente, respeto a unas reglas de mayorías tan selectivas que no era difícil que degenerasen en una oligarquía de facto). Dentro de este conjunto de valores y rasgos, hay que incluir en un lugar privilegiado la prohibición de atentar contra la naturaleza de una manera tan firme que comprometa la supervivencia humana sobre la Tierra. Inicialmente, el hombre debe respeto, reverencia y cuidado a la naturaleza en virtud del origen común que los emparenta; en la medida que el hombre «también-es-naturaleza» participa de su esencia y comparte sus rasgos, originando un lazo de fraternidad con esta realidad con la que está hermanado.

A esta razón biológica hay que sumar un fundamento utilitarista. En efecto, el hombre debe venerar al medio que le proporciona los recursos naturales necesarios para sostener su vida. Sin elementos naturales no existiría vida humana, y su conservación y mantenimiento en el estado actual es requisito esencial e insoslayable para la supervivencia humana. Atentar contra las bases biológicas que sustentan la vida no es sólo un ecocidio, sino un suicidio genocida. Esta idea debe alzarse como criterio de contraste del actual sistema económico y social: si sus efectos son contrarios a este fundamento, debe rechazarse por antiecológico e inhumano, e indagar en otras alternativas.

Por todo ello, la protección del medio debe situarse en el centro de gravedad de las concepciones jurídico-políticas de cualquier sistema democrático. Esta reubicación debe plasmarse en la consideración de que sobre la vida (y en especial, sobre la no-vida) no puede decidirse a través de ningún género de mayoría, de manera que cualquier decisión de naturaleza ambiental que pueda comprometer las bases biológicas que sustentan la vida (la planetaria en general y la humana en particular) debe considerarse no sólo antiecológica sino antidemocrática. Esta opción, por tanto, bien puede entenderse que instaura una suerte de límite material a los tradicionales criterios de democracia formal legitimadora de las decisiones adoptadas conforme a sus métodos. En un plano teórico, esta suerte de «pacto natural» nos obliga a mirar y revisar expresiones tan tradicionales como las de "pacto social» o «contrato social». Lo que está en juego es la misma supervivencia humana, y no una entidad política de dudosa consistencia empírica en términos ecológicos. Poco importa que la catástrofe ecológica la perpetre una sociedad equitativa que respeta por encima de todo las reglas del juego democrático; si esta sociedad no respeta las reglas materiales (reales, esto es, naturales) impuestas por los ecosistemas particulares y por el mundial, será únicamente una buena sociedad a recordar.

\section{Científicos y medio ambiente}

La comunidad científica debe jugar un papel extraordinario en la promoción y avance hacia una sociedad más ecoló- 
gica y respetuosa con el medio ambiente.

Actualmente, los científicos disponen de unos medios de investigación y acción de los que la humanidad no ha disfrutado jamás y que eran impensables hace sólo cincuenta años. Esta capacidad presenta la virtud de que pueden suponer una ayuda inestimable para la solución de la crisis ambiental, aunque por sí sola insuficiente. Pero a la vez, puede convertirse en el elemento decisivo para acelerar el proceso de deterioro natural que nos acerque a la catástrofe ecológica final.

La comunidad científica dispone de los conocimientos y herramientas necesarias para acercarnos a uno u otro fin, y de esta circunstancia deriva su más intensa responsabilidad ambiental. Los científicos deberían elaborar o incluir cláusulas en los códigos deontológicos específicos para cada una de las disciplinas en las que se adscriben (física, química, ingeniería, etc...) que prohiban el uso de sus conocimientos para el desarrollo de investigaciones o programas acción en los que directa o indirectamente puedan producirse daños ecológicos graves, o que simplemente perjudiquen a medio o largo plazo el equilibrio o estabilidad ecológica de la zona, especialmente si se va a traducir en consecuencias nocivas para el ser humano.

Entre los científicos, es imprescindible que los ecólogos jueguen un papel importante dentro de este esquema. Su responsabilidad a los efectos de no contribuir al deterioro ambiental es, en principio, idéntica a la exigible al resto de miembros de la comunidad científica.
No obstante, entre éstos deben cumplir una función más destacada y activa en la promoción de las actitudes ecologistas y de abstención de agredir al entorno; su faceta científica y la político-protectora deben confundirse, colaborando con la exactitud de los datos que les proporciona su pericia a apoyar sus ideas ecologistas, y desplegando las investigaciones que más convienen a la conservación del entorno, y no las meramente experimentales y servidoras de proyectos de desarrollo antiecológico.

\section{Desarrollo económico y medio ambiente}

\section{Desarrollarse no es sólo crecer económicamente}

Es indispensable gozar de un mínimo económico existencial que permita el sostenimiento de cualquier vida humana. Disfrutar de unos niveles adecuados de renta proporciona, además, el acceso a bienes de consumo y posibilidades culturales esenciales en el contexto social mundial actual. Sin estos niveles de renta difícilmente puede aspirarse a llevar una vida razonablemente satisfactoria. Por tanto, desarrollarse debe equivaler a crecer económicamente cuando los niveles de renta no posibilitan el acceso a una vida digna y a bienes culturales elementales. No obstante, cubiertas estas necesidades primarias el crecimiento económico deja de ser un valor primario para pasar a ocupar una posición pasiva. Si no es así, la ilusión de crecer sin límite se traduce en saqueos ambientales insostenibles ecoló- 
gicamente. Al igual, la agresión más sutil aunque no menos rotunda al ser personal que produce este criterio es directamente proporcional al grado de asimilación social e institucional del mismo. Es imprescindible, en consecuencia, afirmar que todo desarrollo debe ser humano, que favorezca la calidad de vida por encima del nivel de vida, de tal manera que en ningún caso pueda entenderse que la variable del Producto Interior Bruto o la renta per capita son matemáticamente fiables como medidores del grado de felicidad personal que disfrutan los miembros de una determinada sociedad.

Este criterio, puede destilarse en el siguiente postulado ético: la economía es un subsistema de la ecología y debe subordinarse a sus leyes y a las reglas de funcionamiento del ecosistema. No existe contradicción entre economía y ecología, sino mutua complementación; la economía debe ajustarse a los ciclos y reglas naturales aprovechando con originalidad sus enormes recursos (energía eólica, solar, productos naturales y fuerzas motrices que requieren escasas inversiones de capital y producen enormes incrementos marginales de bienestar, etc...), y nunca debe perder de vista la insoslayable finitud de los recursos naturales que la componen. Entender que la ecología supone un freno a la actividad económica es sólo un acierto a medias: es un límite y se opone a una economía que persigue un crecimiento material ilimitado y obsesivo, es decir, una "economía anti-económica», abstracta e idealista, que se evade de la realidad al no tomar en consideración los límites naturales inherentes a toda actividad humana.

\section{Solidaridad y medio ambiente}

El Movimiento verde también es militante en temas no estrictamente ecológicos, pero relacionado con éste en virtud del principio metodológico de integridad. Esta preocupación común a todos los grupos de este movimiento es la del desarrollo de los pueblos pobres y su reprcusión en el medio.

Como puto de partida, no consideran éticamente tolerable la subordinación del derecho al desarrollo de los pueblos pobres a los intereses económicos de los países que proporcionan la ayuda en cada momento y situación específica. Lo contrario es inmoral y ecológicamente insostenible. Inmoral porque multiplica la pobreza que «pretende» corregir en proporción al aumento de los rendimientos económicos las empresas y gobiernos de los países desarrollados que prestan al ayuda; esta hipocresía moral debe excluirse de plano por abiertamente inhumana e insolidaria. Pero a la vez, la subordinación de la ayuda al desarrollo a la obtención de beneficios económicos es profundamente antiecológica: al dirigir a los países subdesarrollados hacia una más intensa pobreza, éstos se ven obligados a depredar con más intensidad los recursos naturales para poder seguir subsistiendo. Por tanto, el problema no es únicamente técnico (únicamente es técnica la forma invariable en la que se produce el fenómeno una vez iniciado), sino de actitud, a saber: es el criterio ético egoísta o realmente solidario con el que se preste la ayuda, el que nos va a permitir calificar como moral o inmoral la acción de ayuda concreta. 
Dentro de este contexto, es obligado prestar una atención especial a la ayuda tecnológica que se presta a los países subdesarrollados para hacer efectivo su derecho al desarrollo. De ninguna manera ésta pueda ser una tecnología intensiva en capital y baja en mano de obra, que incorpore tecnología avanzada y exija conocimientos superiores para su uso. Con éste género de tecnología únicamente se conseguirá aumentar las bolsas de pobreza, dificultar el mantenimiento y uso de la tecnología y favorecer la ruptura social separando las clases cultas, ricas y conocedoras de los procesos complejos y la masivamente analfabeta y desempleada. Hay que recurrir a la tecnología intermedia para alcanzar los niveles de desarrollo deseado en estas naciones. Este género de ayuda tecnológica, que combinan capital y mano de obra (por ejemplo, entregando animales en vez de tractores, costosos de mantener y que exigen poca mano de obra) tiene virtudes excelentes, a saber:

- favorece tanto el crecimiento económico en términos de Producto Interior Bruto al tiempo que el reparto equitativo de la riqueza entre todos los estratos de la sociedad;

- es una tecnología accesible a todos, que puede utilizarse con escasos conocimientos y en no pocos supuestos por analfabetos o personas sin ninguna instrucción en la misma, a la cual puede ponerse al tanto de los conocimientos necesarios en muy pocas sesiones;

- es una tecnología que no excluye el trabajo humano, sino que lo implica como elemento imprescindible, colaborando de forma decisiva al desa- rrollo humano proveniente del ejercicio de la propia profesión;

- no es un producto culturalmente uniforme que excluya la cultura y creencias de cada pueblo al que se destina, sino que la coloca en sus propios cimientos, combinándola con las nuevas creaciones y propuestas para favorecer un desarrollo equilibrado y respetuoso con la antropología cultural de cada área

- por fin, ecológicamente es impecable: no agrede al entorno porque simplemente no puede hacerlo, al precisar de éste para su propio desenvolvimiento, y estar en una relación de dependencia muy cercana.

Esta tecnología es actualmente la única que razonablemente puede colaborar a la superación de la crisis económica de los países subdesarrollados, y de la ambiental de todas las naciones del Planeta. Indudablemente, la tecnología intermedia exige soluciones imaginativas y creaciones originales; pero, al fin y al cabo, qué tecnología no lo ha exigido. La tenaz aplicación de la inteligencia al desarrollo de esta nueva herramienta de progreso, y la el concurso de las voluntades políticas, empresariales y de los destinatarios de las mismas serán los elementos claves para erigirla en un instrumento imprescindible de una nueva forma de desarrollo ecológico y humano.

\section{Los castigos ambientales}

Desde el principio, los movimientos verdes han reivindicado un cuadro de sanciones adecuadas para los que causa- 
ban daños a la Naturaleza. De hecho, se atribuye a la presión de estos movimientos el que se incluyera el apartado tercero en el artículo 45 de la Constitución Española, que dispone: «Para quienes violen lo dispuesto en el apartado anterior, en los términos que la Ley fije se establecerán sanciones penales 0 , en su caso, administrativas, así como la obligación de reparar el daño causado».

Si tuviéramos que sintetizar la postura de los movimientos verdes sobre las sanciones ambientales, las podemos aglutinar en lo que referimos en los apartados siguientes.

\section{a) Principio de preferencia de la prevención}

Sostiene la creación de instrumentos efectivos que anticipen y corrijan los posibles riesgos con anterioridad a la producción del fenómeno agresor del medio ambiente. Para ello hay que fomentar la colaboración de los potenciales agentes contaminantes y crear nuevas formas de ayuda al cumplimiento de las obligaciones ambientales que le son exigibles. En esta primera área de acción elemental las nuevas creaciones deben, obviamente, ir más allá de las tradicionales formas de prevención del derecho sancionador, esto es, del mero castigo. Se trata más bien de desarrollar programas activos de colaboración. De entre todas las posibles, es forzada la referencia a la articulación de beneficios fiscales para los agentes contaminantes que acometan «reformas verdes» y soportan obligaciones ambientales. Asimismo, a las empresas menos solventes y que tienen que acometer refor- mas más costosas deberá ofrecérseles modalidades de ayudas financieras específicamente destinada a sufragar sus "gastos ambientales», y que pueden ir desde la modalidad de los «créditos blandos» a las donaciones compensadas con los impuestos devengados por las mismas o las otorgadas a fondo perdido.

A ello debe sumarse la obligación de constituir seguros ambientales para las empresas más importantes y con un mayor riesgo de generar un importante daño ambiental. Esta no es una regla preventiva en sentido estricto, pero obliga a la entidad aseguradora a exigir a la entidad asegurada el cumplimiento de los unos estándares de seguridad adecuados y, en todo caso, forma parte del tejido de previsiones serenamente construidas para paliar los efectos de un posibles desastre ambiental.

\section{b) Proporcionalidad sancionadora}

Con carácter general, es fundamental el mantenimiento de sanciones que, dentro de la proporcionalidad que debe ser inherente a toda norma penal, sean elevadas. Cuando las sanciones sean de naturaleza pecuniaria, especialmente en el ámbito administrativo, siempre deben ser lo suficientemente importantes como para evitar que forme parte de forma corriente de la balanza de pagos previsibles de la entidad contaminante. Si son privativas de libertad, no deben ser tan bajas que siempre se traduzcan en remisiones condicionales de condena que exigen una reiteración improbable para que se lleven a la práctica. 


\section{c) Mejora de los criterios de responsabilidad civil}

Debe mantenerse en este contexto el principio de inversión de la carga de la prueba por responsabilidad extracontractual y de obligación de observar la máxima diligencia exigible, que son la regla general en estos procedimientos. Algunos autores incluso han querido trasladar al ámbito ambiental este principio, dotándolo de un nivel de exigencia más elevado y en consonancia con las necesidades que venimos exponiendo. Así, por ejemplo, Agustín Domingo ha avanzado lo que denomina principio de probabilidad suficiente: los tribunales podrían obligar a una determinada empresa a realizar las reparaciones necesarias para corregir algún punto o elemento de la misma sobre el que existe convicción suficiente de que puede producir un daño ambiental.

No obstante estas sugerencias, la importancia de la materia hace deseable que se progrese con mayor rapidez que en otras áreas sociales hacia la responsabilidad objetiva, siendo ésta una exigencia urgente en aquellos supuestos en los que el riesgo potencial es muy intenso. Esta nueva configuración determinaría la suscripción de pólizas de seguros adecuadas que, en última instancia, garantizarían una razonable reparación del daño causado y, en todo caso, la exigencia de un alto grado de prevención por parte de la entidad aseguradora para evitar el siniestro.

Esta última idea de reparación es fundamental dentro del nuevo derecho ambiental sancionador. Generalmente, se insiste sobre los aspectos indem- nizatorios, soslayándose la idea de reparación, fundamental dentro del contexto de debate ambiental. Dentro de los procedimientos penales, las asociaciones ecologistas deberían jugar un papel fundamental en la formulación de esta reclamación. La sensibilización social desempeñará también un papel protagonista.

\section{d) Principio in dubio pro natura}

Este principio opera dentro de los programas de investigación y cálculo de los efectos ambientales que puede producir el desarrollo de una acción humana sobre un determinado territorio o área ecosistémica. Este principio impone la obligación de renunciar al proyecto en cuestión si existen dudas razonables sobre su viabilidad ambiental. La naturaleza accedería así a una posición sensatamente privilegiada dentro de la escala de valores y prioridades humana. De alguna manera, este principio no es más que una manifestación importante de la idea de desarrollo sostenible: ambos principios propugnan la defensa de los valores ambientales como soportes de la vida humana, y la necesidad de adaptación a sus reglas para gozar de garantías de estabilidad vital, social y económica.

Algunos de estos principios son ya una realidad.

\section{Notas}

${ }^{1}$ Schumacher, E. F, «Replanteando nuestros modos de vida», Integral, 42, 1983, p. 6.

${ }^{2}$ Soriano, R, Derechos Fundamentales y Valores Jurídicos, MAD, Sevilla, 1999, p. 67. 